\title{
Synthesis of Poly(isothianaphthene) by Photopolymerization of 1,3-Dihydroisothianaphthene
}

\author{
Masakazu Kitano, Tomokazu IYoda, and Takeo SHIMIDzu* \\ Division of Molecular Engineering, Graduate School of Engineering, \\ Kyoto University, Sakyo-ku, Kyoto 606-01, Japan
}

(Received January 6, 1995)

\begin{abstract}
A conducting polymer, poly(isothianaphthene) (PITN) was prepared by direct photopolymerization in solution of 1,3-dihydroisothianaphthene (DHITN) which was more stable in air than isothianaphthene (ITN). This photopolymerization was initiated with electron transfer from DHITN to an acceptor such as carbon tetrachloride or oxygen. It proceeded by both UV irradiation and cationic polymerization under light exclusion. The polymerization rate was accelerated by the addition of salts. The rate of the PITN fraction of the product composition was governed by the nucleophilicity of the anion species of added salts. The features of this polymerization were seen in electrochemical polymerization and photopolymerization of ITN.

KEY WORDS Poly(isothianaphthene) / Photopolymerization / Dihydroisothianaphthene /
\end{abstract}

Recently, special interest has been drawn to a small band-gap polymer in experiential and theoretical approaches. Poly(naphthothiophene), ${ }^{1}$ poly(dithieno-thiophene),${ }^{2-4}$ poly(thienobenzene), ${ }^{5}$ and poly(dioxymethyleneisothianaphthene) ${ }^{6}$ were recently synthesized. The band gaps of some polymers were calculated. ${ }^{7-12}$ In the conducting polymers, poly(isothianaphthene) (PITN) has a smallest band gap $(1.1 \mathrm{eV})$ and the conducting doped state gives transparency in visible region. ${ }^{13-14}$ Both conspicuous properties are explained by the large quinoidic character of the polymer backbone geometry or electronic structure. ${ }^{15-17}$ PITN has so far been prepared by electrochemical or chemical polymerization ${ }^{18}$ of its monomer, isothianaphthene (ITN).

Recently, we reported a new preparative method of PITN by the direct photopolymerization of ITN to provide photochemical micro-fabrication of PITN-based electrically conducting polymer thin film. ${ }^{19}$ However, ITN is unstable in air.

1,3-dihydroisothianaphthene (DHITN) is the intermediate of ITN and more stable in air. DHITN was first described by Leser ${ }^{20}$ and later by Hjelt. ${ }^{21}$ Many synthetic routes ${ }^{2-31}$ and properties ${ }^{32-35}$ were investigated. In the report by Whitehead et al., ${ }^{22}$ hint of the polymerization of DHITN with oxygen is described. Jen et al. reported the oxygen-induced polymerization of DHITN gave PITN ${ }^{36}$ but the details of this polymerization are not clearly described.

Here, we report the details of this oxygeninduced polymerization of DHITN, that is, the photopolymerization of DHITN.

\section{EXPERIMENTAL}

\section{Analysis}

The UV-VIS absorption spectra were recorded on a Shimadzu MPS-2000 or Shimadzu UV-2200 spectrophotometer and fluorescence spectra were recorded on a Shimadzu RF-503A spectrofluorometer. ${ }^{1} \mathrm{H}$ NMR and ${ }^{13} \mathrm{C}$ NMR spectra were recorded on a JEOL EX-90 spectrometer. Infrared absorption spectra were recorded on a Nicolet 20 DXB spectro- 
meter. The in situ spectra were recorded on a Otsuka electronics multichannel photodetector (MCPD) controlled by a Fujitsu PC 9801 computer.

\section{Syntheses}

DHITN was synthesized according to Cava's method $^{23}$ and purification was confirmed by ${ }^{1} \mathrm{H}$ NMR, ${ }^{13} \mathrm{C}$ NMR, and UV-VIS absorption spectra.

ITN was synthesized according to Wudl's method $^{13}$ and purification was confirmed by ${ }^{1} \mathrm{H}$ NMR and UV-VIS absorption spectra.

Authentic PITN was prepared according to Wudl's method ${ }^{13}$ by the electrochemical polymerization of ITN in acetonitrile solution containing $0.1 \mathrm{~mol} \mathrm{dm}^{-3}$ tetrabuthyl ammonium bromide (TBABr) at $0.6 \mathrm{~V}$ vs. SCE or by the chemical polymerization of ITN with sulfuric acid. The PITN film contained a small amount of poly(1,3-dihydroisothianaphthene) (PDHITN), about 9\%, which was estimated by the infrared spectrum and elemental analysis. (Elemental analysis. Calcd for $\left(\mathrm{C}_{8} \mathrm{H}_{4} \mathrm{~S}\right)_{0.921}\left(\mathrm{C}_{8} \mathrm{H}_{6} \mathrm{~S}\right)_{0.09} \mathrm{Br}_{0.015}\left(\mathrm{H}_{2} \mathrm{O}\right)_{0.307}$ : $\mathrm{C}, 68.5 \%$; H, 3.4\%; S, 22.85\%; Br, 0.85\%: Found: C, 68.5\%; H, 3.4\%; S, 22.7\%; Br, $0.86 \%$. IR spectral data: $v_{\mathrm{C}=\mathrm{s}}, 1150 \mathrm{~cm}^{-1} ; v_{\mathrm{C}=\mathrm{C}}$ of thiophene ring, $980 \mathrm{~cm}^{-1}$.)

Authentic PDHITN was also prepared according to Wudl's method ${ }^{13}$ by the electrochemical polymerization of ITN in acetonitrile solution containing $0.1 \mathrm{~mol} \mathrm{dm}^{-3}$ tetrabuthyl ammonium perchlorate $\left(\mathrm{TBAClO}_{4}\right)$ at $1.0 \mathrm{~V} v s$. SCE. (IR spectral data: $v_{\mathrm{C}-\mathrm{H}} ; 1420$ and $2500 \mathrm{~cm}^{-1}$.)

\section{Photopolymerization}

Typical photopolymerization was carried out by the irradiation of a deaerated acetonitrile solution containing $0.162 \mathrm{~mol} \mathrm{dm}^{-3}$ DHITN and $3.2 \mathrm{~mol} \mathrm{dm}^{-3}$ carbon tetrachloride as an electron acceptor and $0.162 \mathrm{~mol}$ $\mathrm{dm}^{-3}$ salt with a $500 \mathrm{~W}$ Xe lamp through a monochrometer. The incident photon flux at $334 \pm 3 \mathrm{~nm}$ was $2.1 \times 10^{17}$ quanta $\mathrm{cm}^{-2} \mathrm{~s}^{-1}$ estimated by chemical actinometry using iron(III) trioxalate. The rate of the photopolymerization of DHITN in acetonitrile was determined based on increase of absorbance at $750 \mathrm{~nm}$ that was recorded on MCPD.

\section{RESULTS AND DISCUSSION}

\section{Characterization}

Exposure of DHITN in deaerated acetonitrile to UV irradiation with Xe lamp cause no change in the absorption spectrum. In the presence of carbon tetrachloride, this transparent solution turned blue by UV irradiation for a few minutes. After irradiation for 100 minutes, a black precipitate was obtained. The infrared spectrum of the black precipitate is shown in Figure 1(a). The infrared spectra of the black precipitate and authentic PITN corresponded were identical as shown in Figure 1 (b). The peak of $1150 \mathrm{~cm}^{-1}$ was assigned to $\mathrm{C}=\mathrm{S}$ stretching of thiophene rings and the peaks of 980 and $1300 \mathrm{~cm}^{-1}$ were assigned to

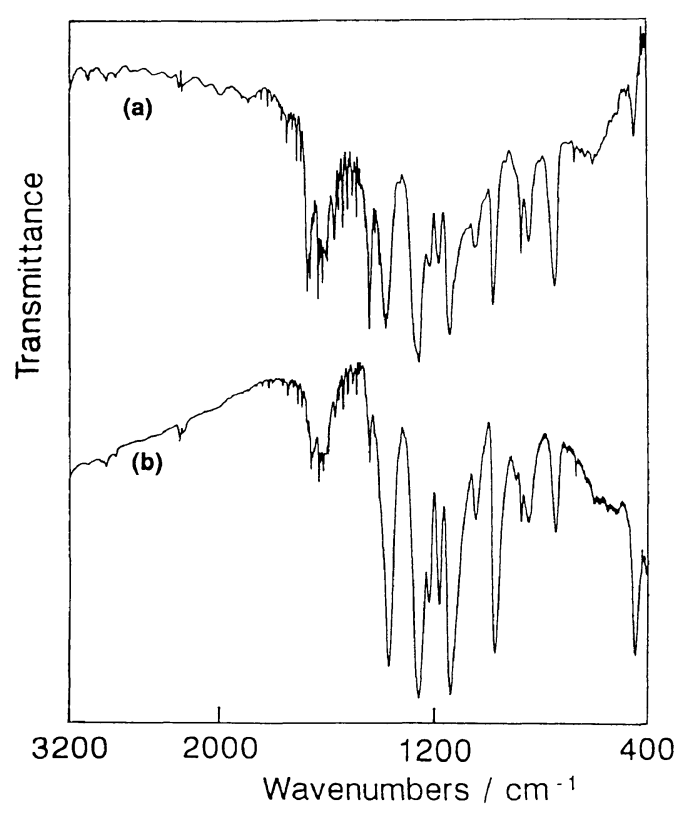

Figure 1. Infrared spectra of (a) black precipitate obtained by UV irradiation, (b) authentic PITN obtained by electrochemical polymerization. 
trans $\mathrm{C}=\mathrm{C}$ stretching of quinoidic structure of PITN. The peak of $770 \mathrm{~cm}^{-1}$ was assigned to $\mathrm{C}-\mathrm{H}$ bending of four adjacent aromatic $\mathrm{H}$. All peaks of the major features of PITN were observed in both infrared spectra. This black precipitate had the structure of PITN.

Elemental analysis of the black precipitate corresponded to PITN. (Calcd for $\left(\mathrm{C}_{8} \mathrm{H}_{4} \mathrm{~S}\right)$ : $\mathrm{C}, 72.7 \%$; H, 3.1\%; S, 24.2\%; Found: C, $67.4 \% ; \mathrm{H}, 3.4 \%$; S, 23.6\%)

We concluded from the infrared absorption spectra and elemental analysis that the precipitate obtained by UV irradiation was PITN by the photopolymerization of DHITN.

\section{Polymerization Mechanism}

Figure 2 shows the optical absorption spectrum of freshly prepared DHITN in acetonitrile. DHITN was freshly distilled under reduced pressure and this solution was prepared under inert atmosphere. In this figure, three peaks were observed at 260,265, and $274 \mathrm{~nm}$. No fluorescence was observed from this solution by UV irradiation. After carbon tetrachloride was added to this DHITN acetonitrile solution, a new absorption peak was observed at $320 \mathrm{~nm}$ and a strong fluorescence was observed at $360 \mathrm{~nm}$ as shown in Figure 3(a) and (b), respectively. Absorption and fluorescence spectra were not assigned to DHITN and carbon tetrachloride. The fluo-

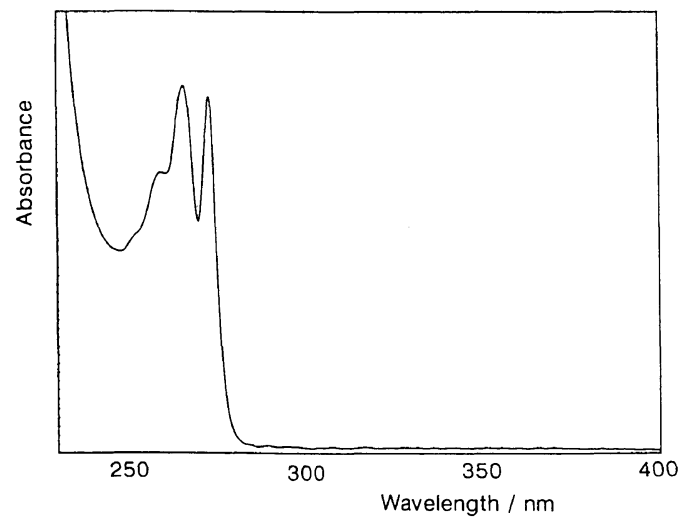

Figure 2. Optical absorption spectrum of freshly prepared DHITN rescence and absorption were enhanced by carbon tetrachloride. These results suggest that a new compound was formed in the solution.

In general, hydrogens at 1,3-position in DHITN are very active and tend to be removed. Compared with ITN possessing an absorption peak at $330 \mathrm{~nm}$ and strong fluorescence peak at $380 \mathrm{~nm}$, the conjugated length of the new compound is smaller than that of ITN. These results suggest that DHITN might be dehydrogenated in solution by carbon tetrachloride. Figure 4 shows the dehydrogenation

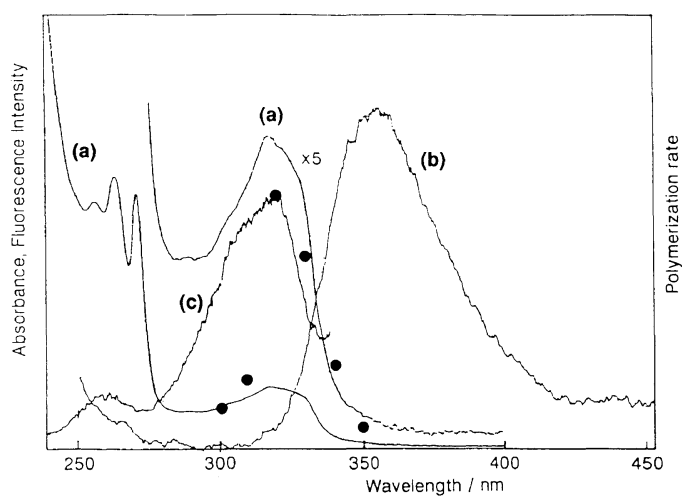

Figure 3(a). Absorption spectrum, (b) fluorescence spectrum, and (c) fluorescence excitation spectrum of fluorescence of DHITN in acetonitrile solution. The circle shows the action spectrum of the primary polymerization rate obtained by based on increase of the optical absorption at $750 \mathrm{~nm}$ in acetonitrile solution containing DHITN and carbon tetrachloride.

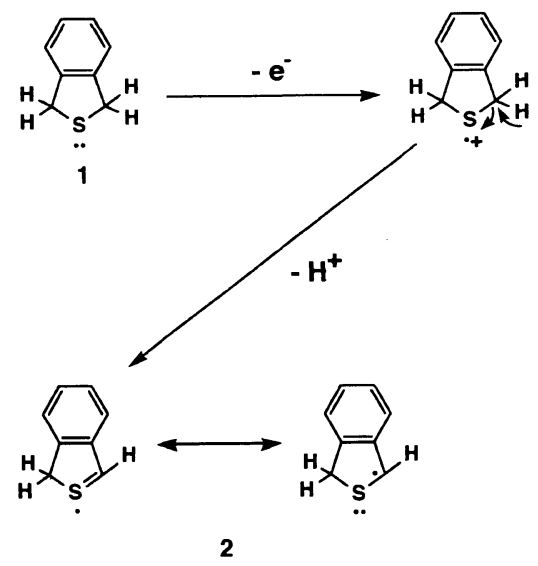

Figure 4. Mechanism of electron transfer and formation of dehydrogenated DHITN. 


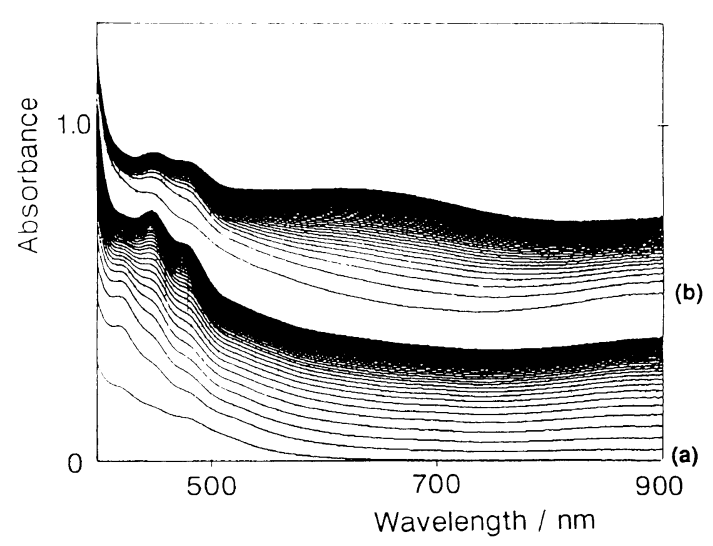

Figure 5. Optical absorption spectrum change of DHITN acetonitrile solution containing carbon tetrachloride after irradiation for 1 minute and stored in the dark. Data were taken in 10 minutes intervals over a period of 6 hours. (a) the first run; (b) the second run.

\section{mechanism of DHITN.}

The absorption band at $320 \mathrm{~nm}$ and fluorescence band at $360 \mathrm{~nm}$ may belong to 2 . The fluorescence excitation spectrum of this compound agreed with the absorption spectrum as shown in Figure 3(c). From these spectra, O-O transition energy of this compound was $3.76 \mathrm{eV}$. In Figure 3, the circle shows an action spectrum of the primary photopolymerization rate obtained by based on increase of optical absorption at $750 \mathrm{~nm}$ in acetonitrile solution containing DHITN and carbon tetrachloride. This action spectrum of the photopolymerization is in good agreement with the absorption spectrum and fluorescence excitation spectrum of $\mathbf{2}$. So we conclude that this photo-polymerization is initiated by the excitation of 2 .

This polymerization proceeded without light after irradiation. Figure 5 shows the absorption spectrum change of DHITN acetonitrile solution containing carbon tetrachloride after irradiation for 1 minute and stored under dark. Data were taken in 10 minute intervals over a period of 6 hours. The polymerization took place for a few hours under light exclusion. Such phenomena were observed on repeated runs.

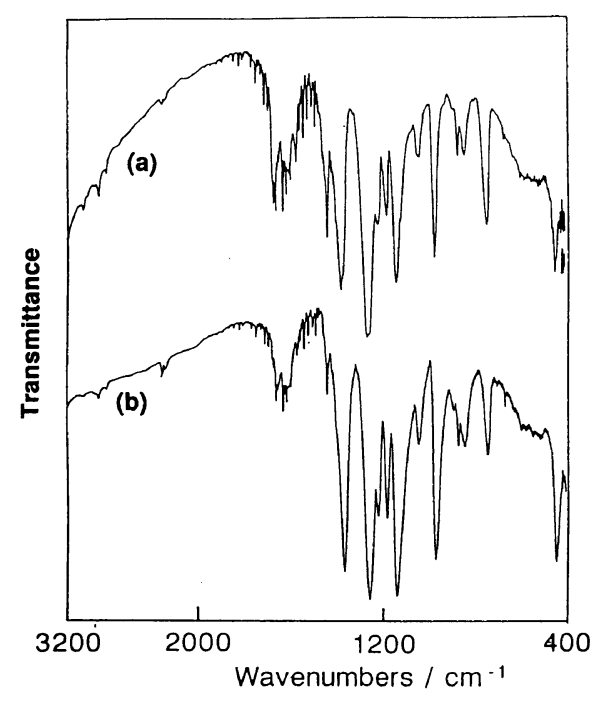

Figure 6. Infrared spectra of (a) black precipitate obtained by irradiation after oxygen blowing, (b) authentic PITN obtained by electrochemical polymerization.

These results lead to the conclusion that the present photopolymerization proceeds by two mechanisms: photopolymerization and photoinduced cationic polymerization.

\section{Photopolymerization with Oxygen}

Oxygen could be used in place of carbon tetrachloride. After oxygen was blown into acetonitrile solution containing DHITN, a black precipitate was obtained by irradiation for few hours. The infrared spectrum of the black precipitate is shown in Figure 6(a). The infrared spectrum of this black precipitate and authentic PITN prepared by electrochemical polymerization were identical as shown in Figure 6(b). The peak of $1150 \mathrm{~cm}^{-1}$ was assigned to $\mathrm{C}=\mathrm{S}$ stretching of thiophene rings and peaks of 980 and $1300 \mathrm{~cm}^{-1}$ were assigned to trans $\mathrm{C}=\mathrm{C}$ stretching of quinoidic structure of PITN. The peak of $770 \mathrm{~cm}^{-1}$ was assigned to $\mathrm{C}-\mathrm{H}$ bending of four adjacent aromatic $\mathrm{H}$. All peaks of the major features of PITN were observed in the two infrared spectra. This black precipitate had the structure of PITN.

Elemental analysis of the black precipitate corresponded to PITN. (Calcd. for $\left(\mathrm{C}_{8} \mathrm{H}_{4} \mathrm{~S}\right)$ : 

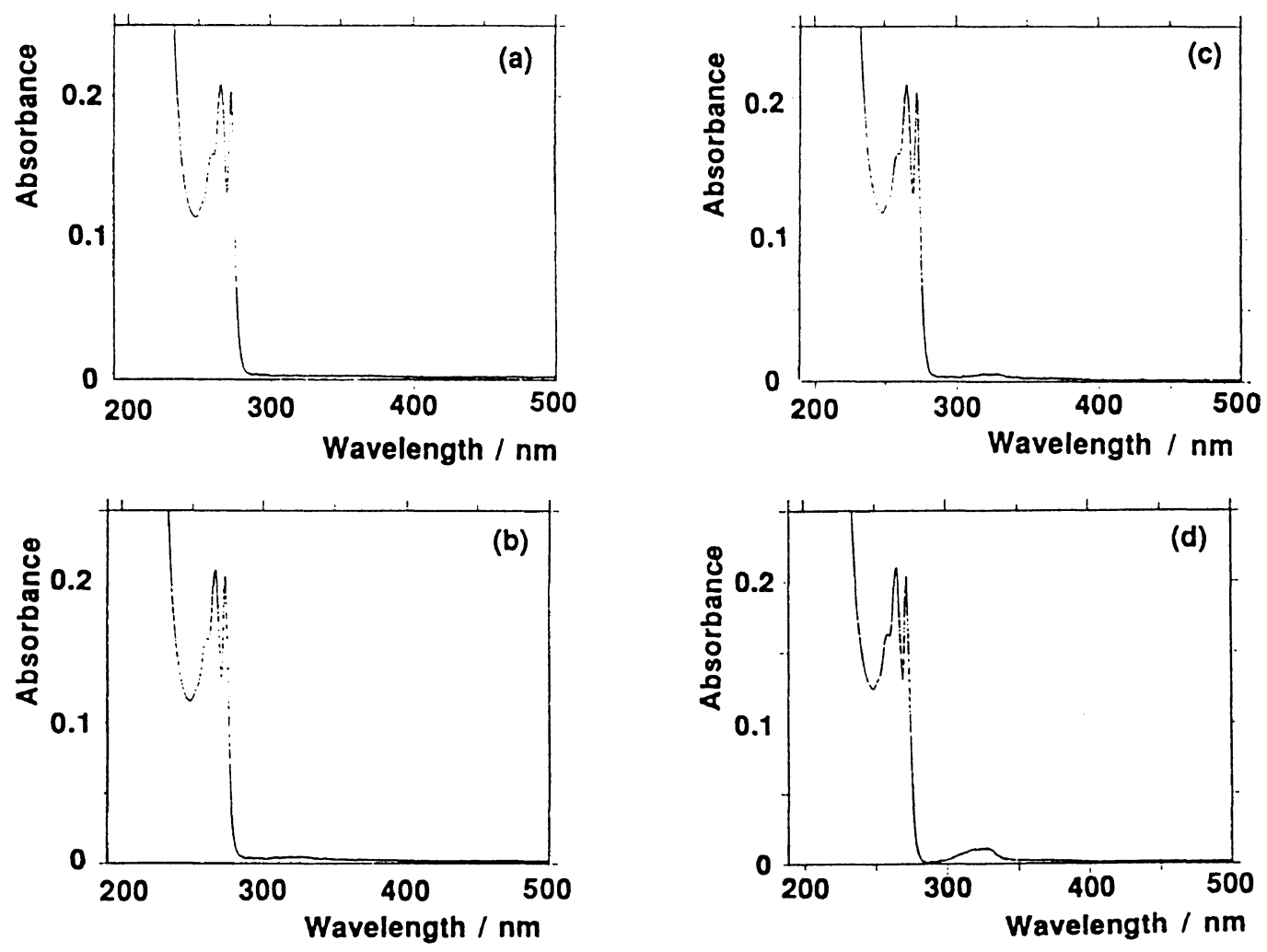

Figure 7. Optical absorption change during oxygen gas blowing. (a) before blowing; (b) after 2 minutes blowing; (c) after 5 minutes blowing; (d) after 30 minutes blowing.

C, $72.7 \% ; \mathrm{H}, 3.1 \% ; \mathrm{S}, 24.2 \%$; Found: C, $66.3 \% ; \mathrm{H}, 3.3 \% ; \mathrm{S}, 23.1 \%$; O, 6.3\%)

We conclude from these infrared absorption spectra and elemental analysis that this black precipitate obtained in DHITN acetonitrile solution exposed to oxygen and UV irradiation is PITN by photopolymerization of DHITN.

Figure 7 shows optical absorption change during oxygen gas blowing. Absorption band at $330 \mathrm{~nm}$ grew with blowing time. From this observation, it is thought that dehydrogenation of DHITN proceeds by oxygen gas blowing. So the absorption band at $330 \mathrm{~nm}$ belonges to this dehydrogenated product.

Figure 8 shows the absorption spectrum and fluorescence spectrum of this product. Two fluorescence spectra were observed in DHITN acetonitrile solution after oxygen gas blow-

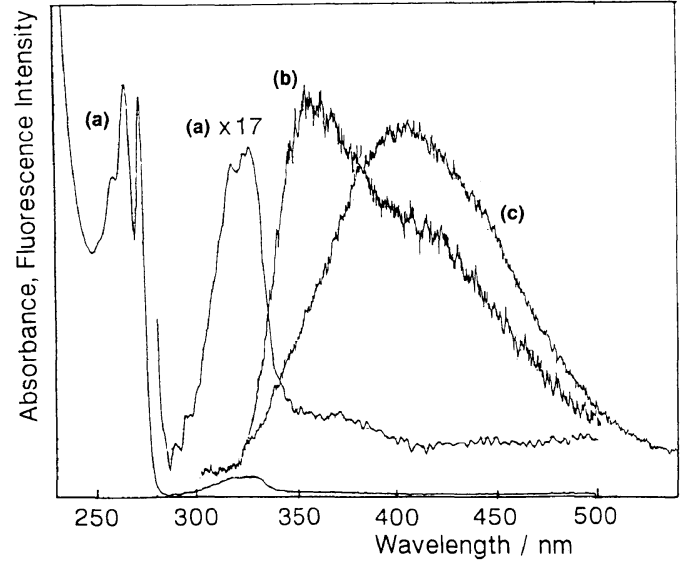

Figure 8. (a) Absorption spectrum, (b) fluorescence spectrum excited at $240 \mathrm{~nm}$, and (c) fluorescence spectrum excited at $300 \mathrm{~nm}$ of DHITN in acetonitrile solution after oxygen gas blowing for 100 minutes 
ing. The fluorescence spectrum of $\lambda_{\max } 360 \mathrm{~nm}$ was observed at an irradiation wavelength of $240 \mathrm{~nm}$. The fluorescence spectrum of $\lambda_{\max }$ $400 \mathrm{~nm}$ was observed at an irradiation wavelength of $280-300 \mathrm{~nm}$. As shown in Figure 8 , this mechanism seems not simple like that of carbon tetrachloride. At least two types of oxidation took place in solution. Attempts to isolate these oxidation products by chromatography were unsuccessful.

\section{Product Composition Rate of PITN and PDHITN}

This photopolymerization was accelerated by added salts. For example, $0.162 \mathrm{~mol} \mathrm{dm}^{-3}$ tetrabuthyl ammonium bromide (TBABr) was added to solution and a black precipitate was obtained within 20 minutes. Such catalytic behavior of added salt was found for every salt. The product composition rates of PITN and PDHITN were affected by the anionic species of added salts. A black PITN precipitate was obtained in the presence of $\mathrm{TBABr}$ or tetrabuthyl ammonium chloride. A yellowish brown product, identified as PDHITN by infrared absorption spectra and ${ }^{1} \mathrm{H}$ NMR, was obtained in the presence of $\mathrm{TBAClO}_{4}$, lithium perchlorate, or lithium tetrafluoroborate as the added salt. Similar dependence of anion on product composition were observed on electrochemical polymerization of ITN using various supporting electrolytes and photopolymerization of ITN using various salts. When the DHITN solution contained a nucleophilic anion species, the proton instantly removed and the chief product was PITN. When the added salt was not a nucleophilic reagent, the cationic polymerization proceeded selectively and the chief product was PDHITN.

\section{CONCLUSION}

A novel synthetic route of PITN by the photopolymerization from DHITN was developed. This photopolymerization was initi- ated by dehydrogenation of DHITN induced with an electron acceptor. It proceeded with irradiation and cationic polymerization under light exclusion. It was accelerated by the added salts, but product composition and rate of PITN fraction were governed by the nucleophilicity of the anion species of added salts. Similar dependence of anion was observed in the electrochemical polymerization and photopolymerization of ITN.

\section{REFERENCES}

1. Y. Ikenoue, Synth. Met., 35, 263 (1990).

2. C. Taliani, G. Ruani, R. Zamboni, A. Bolognesi, M. Catellani, W. Porzio, and P. Ostoja, Synth. Met., 28, C507 (1989).

3. A. Bolognesi, M. Catellani, S. Destri, R. Zamboni, and C. Taliani, J. Chem. Soc., Chem. Commun., 246 (1988).

4. S. Luzzati, C. Botta, M. Catellani, R. Zamboni, G. Ruani, C. Taliani, and R. Tubino, Synth. Met., 41-43, 1319 (1991).

5. A. Bolognesi, M. Catellani, S. Destri, W. Porzio, R. Danieli, S. Rossini, C. Taliani, R. Zamboni, and P. Ostoja, Synth. Met., 28, C521 (1989).

6. Y. Ikenoue, F. Wudl, and A. J. Heeger, Synth. Met., 40, 1 (1991).

7. M. Kertesz and Y.-S. Lee, Synth. Met., 28, C545, (1989).

8. K. Tanaka, S. Wang, and T. Yamabe, Synth. Met., 30, 57 (1989).

9. P. Otto and J. Ladik, Synth. Met., 36, 327 (1990).

10. J. L. Bredas, Synth. Met., 17, 115 (1987).

11. J. L. Bredas, J. Chem. Phys., 82, 3808 (1985).

12. Y.-S. Lee and M. Kertesz, J. Chem. Phys., 88, 2609 (1988).

13. M. Kobayashi, M. Boysel, F. Wudl, and A. J. Heeger, J. Chem. Phys., 82, 5717 (1985).

14. F. Wudl, M. Kobayashi, N. Colaneri, M. Boysel, and A. J. Heeger, Mol. Cryst. Liq. Cryst., 118, 199 (1985).

15. J. L. Bredas, B. Themans, J. M. Andre, A. J. Heeger, and F. Wudl, Synth. Met., 11, 343 (1985).

16. J. L. Bredas, J. Chim. Phys., 84, 627 (1987).

17. J. L. Bredas, A. J. Heeger, and F. Wudl, J. Chem. Phys., 85, 4673 (1986).

18. F. Wudl, M. Kobayashi, and A. J. Heeger, J. Org. Chem., 49, 3382 (1984).

19. T. Iyoda, M. Kitano, and T. Shimidzu, J. Chem. Soc. Chem. Comm., 22, 1618 (1991).

20. G. Leser, Ber., 17, 1824 (1884).

21. E. Hjelt, Ber., 22, 2904 (1889).

22. S. F. Birch, R. A. Dean, and E. V. Whitehead, $J$. Inst. Petroleum, 40, 76 (1954). 
23. M. P. Cava and A. A. Deana, J. Am. Chem. Soc., 81, 4266 (1959).

24. W. G. Toland and R. W. Gampbell, J. Org. Chem., 28, 3124 (1963).

25. R. H. Schlessinger and I. S. Ponticello, J. Chèm. Soc., Chem. Commun., 1013 (1969).

26. J. A. Gladysz, V. K. Wong, and B. S. Jick, Tetrahedron, 35, 2329 (1979).

27. D. N. Harpp and J. G. MacDonald, Tetrahedron Lett., 25, 703 (1984).

28. W. D. Crow and Y. T. Pang, Aust. J. Chem., 37, 1903 (1984).

29. K. Steliou, P. Salama, and J. Corriveau, J. Org. Chem., 50, 4969 (1985).
30. S. Fujisaki, I. Fujiwara, Y. Norisue, and S. Kajigaeshi, Bull. Chem. Soc. Jpn., 58, 2429 (1985).

31. R. Grigg, R. Scott, and P. Stevenson, J. Chem. Soc., Perkin Trans. 1, 1357 (1988).

32. H. Kloosterziel and J. A. A. van Drunen, Tetrahedron Lett., 13, 1023 (1973).

33. W. Adcock and B. D. Gupta, J. Org. Chem., 41, 1498 (1976).

34. K. Kobayashi, K. Ohno, T. Ishida, S. Masuda, and Y. Harada, Chem. Lett., 257 (1987).

35. A. G.-Keller, P. Szczecinski, and H. Koziel, Magnetic Resonance in Chemistry, 26, 468 (1988).

36. K-Y. Jen and R. Elsenbaumer, Synth. Met., 16, 379 (1986). 